\title{
기술자료
}

$$
\begin{gathered}
\text { 국가 대기정책수립 및 평가를 위한 대기질 모델링 가이드라인 } \\
\text { - Part I 일반 사항 - } \\
\text { 이대균* 이용미* 이미향* · 홍성철** · 홍지형* }
\end{gathered}
$$

국립환경과학원 대기공학연구과*, 국립환경과학원 기후변화연구과**

(2013년 8월 20일 접수, 2013년 9월 13일 승인)

\section{Air quality modeling guideline for national air policy development and evaluation - Part I General information -}

\author{
Dae-Gyun Lee* · Yong-Mi Lee* · Mi-Hyang Lee* · Sung-Chul Hong** · Ji-Hyung Hong* \\ Atmospheric Engineering Research Division, National Institute of Environmental Research, Korea* \\ Climate Change Research Division, National Institute of Environmental Research, Korea**
}

(Manuscript received 20 August 2013; accepted 13 September 2013)

\begin{abstract}
In the Seoul Metropolitan Area(SMA) photochemical air pollutants, nitrogenic compound and particulate matters have increased substantially due to mobile sources, power plants and so on. Therefore 'Special Act on Seoul Metropolitan Air Quality Improvement' was enacted on 2003 in order to improve air quality in the SMA. According to the Special Act, Central and local government have developed the state implementation plan(SIP) to reduce air pollutant emissions from various local sources. One of the key elements of the SIP development is the air quality modeling since modeling results can be used to establish emissions control strategies as well as to demonstrate attainment of air quality goals for ozone, particulate matter, and so on. Air quality modeling, therefore, can be usefully utilized to investigate the effects of government's efforts according to control strategies or measures. Using the air quality model, we can determine whether the implementation plan should be revised or not. A number of questions, however, has been raised concerning accuracy, consistency and transparency of modeling results because if we do not trust modeling results, all the measures dependent on modeling becomes in vain. So, without dealing with these questions, we can not guarantee the reliability and utilizability of air quality modeling results.

In this study, we tried to establish standard methodology for air quality modeling in order to ensure consistency and transparency of modeling results used in the development and evaluation of national air policy. For this purpose, we established air quality modeling guideline to provide
\end{abstract}


or recommend modeling procedures, vertical and horizontal domains, input data of meteorological and air quality modeling and so on.

Keywords : air quality modeling, modeling guideline, modeling procedures, standard domain, input data

\section{I. 서 론}

우리나라 수도권은 대기오염 수준이 전반적으로 악화되는 광역오염현상이 두드러지게 나타나고 있다 (김운수, 2002). 우리나라 환경부에서는 수도권의 광 역적 오염현상을 개선하고 대기오염원을 체계적으로 관리함으로써 지역주민의 건강을 보호하고 쾌적한 생활환경을 조성하기 위하여 2003년 12월 수도권대 기환경개선에 관한 특별법을 제정하여 시행하고 있 다(환경부, 2010). 이에 따라 10년 마다 수도권대기 환경관리 기본계획을 수립하고, 이를 시행하기 위한 세부 시행계획을 마련하여 매년 시행계획 추진 실적 을 보고하고 있다. 그러나 이러한 시행계획 추진 실 적에 따라 삭감되는 배출량과 대기오염도 간의 효과 분석이 일치하지 않는 현상이 발생함에 따라 대기질 모델링을 통한 정책 평가 방법의 필요성이 제안되어 유용하게 사용되어왔다(유철 등, 2011 ; 이종범 등, 2005 ; 홍유덕 등, 2003 ; 김희강 등, 1999). 이러한 모델링 결과의 정책 활용도 제고를 위해서는 신뢰성 있고 정확도가 높은 결과를 산출하는 것이 필수적이 며, 이를 위한 기상 및 배출량 등의 입력 자료의 검증 연구가 선행되어야 한다(국립환경과학원, 2010; Byun et al., 2007). 지금까지 이러한 기상 자료와 배출량 등과 같은 입력 자료 검증과 모델에 대한 불 확실성 개선 및 민감도 분석 등의 연구를 통해 대기 질 모델링 전반의 신뢰성을 향상시켜왔다(홍성철 등, 2012 ; 문난경 등, 2011 ; 김순태 · 이종범, 2011; 이종 범 등, 2009). 그러나 이러한 다양한 연구에도 불구 하고 모델링 관련 연구는 비연속적이고 단편적인 연 구 수행으로 인하여 대기질 정책 수립 및 평가 등에 필요한 표준화 자료와 방법론 등의 일련의 수행 체계 에 대한 기준 마련은 미흡한 실정이었다.

따라서 본 연구를 통하여 대기정책 수립과 평가에
필요한 대기질 모델링 수행시 발생할 수 있는 잠재적 문제점을 제어하고, 대기질 변화의 효과적 예측 모델 인 3 차원 광화학 모델링 수행의 체계적인 방법론을 마련하기 위하여 대기질 모델링 수행절차에 대한 표 준 방법론을 제안하고자 한다. 본 연구의 내용은 대 기질 모델링 수행절차 및 평가방법 등에 대하여 일반 적인 기준을 제시·권고한 것으로 모델 선정, 도메인 설정, 기상 및 대기질 모델링 입력자료 준비 등 일반 적인 사항에 대하여 설명하였다.

\section{II. 대기질 모델링 가이드라인 개요}

미국에서는 일 반적으로 시행계획 (State Implementation Plan)의 작성 및 달성여부를 판단 하기 위한 목적으로 대기질 모델링을 활용하고 있다. 미국 내 시행계획 모델링 프로젝트는 새로운 대기환 경기준의 공표와 함께 시작하여 매 5 년마다 기존의 대기환경기준을 검토하고 새로운 환경기준을 제시하 도록 하고 있다(국립환경과학원, 2010). 또한 미국 $\mathrm{EPA}$ 에서는 PM2.5, 오존, 지역연무(Regional Haze) 등에 관한 문제에 대해 국가 정책 시행을 위한 대기 질 모델링 평가 및 기술적 분석을 위한 가이드라인을 마련하여 제시하고 있다(U.S. EPA, 2007). 이러한 가이드라인에서는 모델 및 설정에 대한 일반적인 권 고 사항과 결과의 이용 및 분석 방법 등 대기정책 평 가를 위한 대기질 모델의 활용을 위한 방법론 및 권 고 사항을 포함하고 있다.

본 연구에서는 미국의 가이드라인과 국내 모델링 관련 연구 자료 그리고 전문가 그룹과의 토의 등을 통하여 기본계획, 시행계획 등 국가 대기정책 수립 및 평가에 사용되는 대기질 모델링 수행을 위한 가이 드라인을 마련하였다. 
Table 1. Recommended air quality models

\begin{tabular}{c|c}
\hline \hline Air quality models & Reference \\
\hline CAMx & Environ(2006) \\
\hline CMAQ & U.S. EPA(1998) \\
\hline UAM-V & Systems Applications International(1996) \\
\hline \hline
\end{tabular}

\section{III. 대기질 모델링 공통 사항}

\section{1. 대기질 모델 선정}

본 연구에서 지칭하는 대기질 모델은 3차원 광화 학 격자 모델을 의미하는 것으로 기상 모델, 배출량 모델 및 대기 물리·화학·침적 모델로 구성된 모듈화 된 모델링 시스템을 의미한다. 이러한 대기질 모델은 인터페이스 결과의 문제점으로 대기질 모델의 선정 에 따라 기상 및 배출량 모델의 선택에 막대한 영향 을 미친다. 그러므로 대기질 모델링 수행 시에는 가 장 적합한 대기질 모델의 선정이 선행되어야한다.

대기질 모델링 수행을 위한 최적 모델은 소스코드 가 공개된 모델로써 사용자가 진단평가 및 예측능력 개선 등을 위해 소스코드를 수정할 수 있어야 한다. 대기질 모델 선정 시에 고려되어야 할 중요 요소들은 과거 유사 사례에 대한 적용 여부와 모델링 수행평가 에 대한 만족도, 그리고 모델 설명 및 사용자 안내서 등의 존재여부 등이다. 또한 최신의 모델링 이론 및 기능과 대기질 모델을 비롯한 기상 및 배출량 모델에 대한 경험 여부 등이 포함되어야한다. 대기 중 오존, 미세먼지 등을 모사하는데 널리 사용되고 있는 권장 대 기질 모델을 Table 1에 제시하였다(홍지형 등, 2011).

\section{2. 대기질 모델링 기간의 선정}

최근 컴퓨터 속도 및 저장 장치의 발달로 장기간의 모델링 실행이 가능하나 모델링 수행 결과를 해석에 는 시간적 제약, 장기분석의 어려움 등 많은 현실적 인 문제로 인하여 대상 오염물질의 특성, 대기환경기 준 등을 고려하여 적정 모델링 기간을 선정할 수도 있다. 오존을 대상 물질로 모델 수행평가 및 배출량 저감대책의 효과를 분석하기 위해서는 최소한 종관 순환 전 기간 또는 오존 시즌 전 기간이 포함되어야 한다(Hogrefe et al., 2000). 미세먼지의 경우, 연평
균 미세먼지 농도의 개선을 분석하기 위하여 한 해에 전체에 대한 모델링을 수행해야하나, Environ (2004)에서는 계절별로 14일 정도 모델링을 수행할 경우 1 년간의 모델링과 비교하여 불확도 면에서 큰 차이를 보이지 않음을 밝히고 있어 계절별로 최소 14 일 이상의 모델링 기간 선정이 요구된다.

대기질 모델링 기간 선정시 고려해야할 사항으로 는 다양한 기상조건을 고려할 수 있는 기간이어야하 며, 많은 측정소의 관측값들이 대기환경기준을 초과 하거나 근접한 날을 포함하는 기간이어야 한다. 또한 모델링 결과와 비교 가능한 대기질 및 기상 자료가 충분히 존재하는 기간이어야 하며, 이외에도 모델링 결과를 효과적으로 분석 및 해석하기 위하여 필요하 다고 판단되는 날들을 대기질 모델링 기간에 포함하 여야 한다.

\section{3. 모델링 도메인 및 수평·수직 해상도 설정}

\section{(1) 모델링 도메인 설정}

과거에는 하나의 도메인을 사용하여 모델링을 수 행하였지만 최근에는 일반적으로 둥지화(nesting) 기법을 사용하여 여러 개의 도메인을 구성한다. 이 때, 실질적인 모델링 대상지역이 우리나라에 국한되 는 경우에도 기상, 배출량 및 대기오염물질 등의 영 향을 반영하기 위하여 중국이나 일본을 포함하는 동 아시아 도메인부터 한반도 도메인, 권역규모 도메인 등으로 점차 축소하여 둥지화된 도메인이 대상지역 을 포함하도록 설정한다. 모델링 도메인은 바람에 의한 대상지역의 대기오염물질 농도 영향을 고려하 기 위하여 주요 풍상 측을 충분히 포함할 수 있어야 하며, 경계조건으로부터의 영향을 최소화할 수 있어 야한다. 둥지화된 모델링 도메인을 사용하는 경우에 는 모델링 대상지역을 충분히 포함해야하며, 또한 대규모 대기오염물질 배출원을 포함해야 한다. 그리 고 대기질에 영향을 주는 지리적·지형적 특성을 잘 반영하고, 인접지역으로부터의 영향을 충분히 반영 할 수 있도록 설정해야한다. 또한 대상지역의 전형 적인 풍속과 재순환 패턴을 포함할 수 있도록 해야 한다. 
Table 2. Standard domains for meteorological modeling

\begin{tabular}{c|c|c|c|c|c}
\hline \hline Domain Center & \multicolumn{5}{|c}{$126^{\circ} \mathrm{E}, 38^{\circ} \mathrm{N}$} \\
\hline Coordinate System & \multicolumn{5}{|c}{$30^{\circ}, 60^{\circ}$} \\
\hline Standard parallel & \multicolumn{5}{|c}{ Lambert conformal conic } \\
\hline \multirow{2}{*}{\begin{tabular}{c} 
Domain Name \\
\cline { 2 - 6 }
\end{tabular}} & Eastern Asia & the Korea Peninsula & Seoul Metro -politan Area & Honam & Youngnam \\
\cline { 2 - 6 } $\begin{array}{c}\text { Grid size and } \\
\text { number }\end{array}$ & nier_d27_01 & nier_d09_01 & nier_d03_01 & nier_d03_02 & nier_d03_03 \\
\cline { 2 - 6 } & $27 \mathrm{~km}$ & $9 \mathrm{~km}$ & $3 \mathrm{~km}$ & $91 \times 76$ & $85 \times 79$ \\
\hline \hline
\end{tabular}

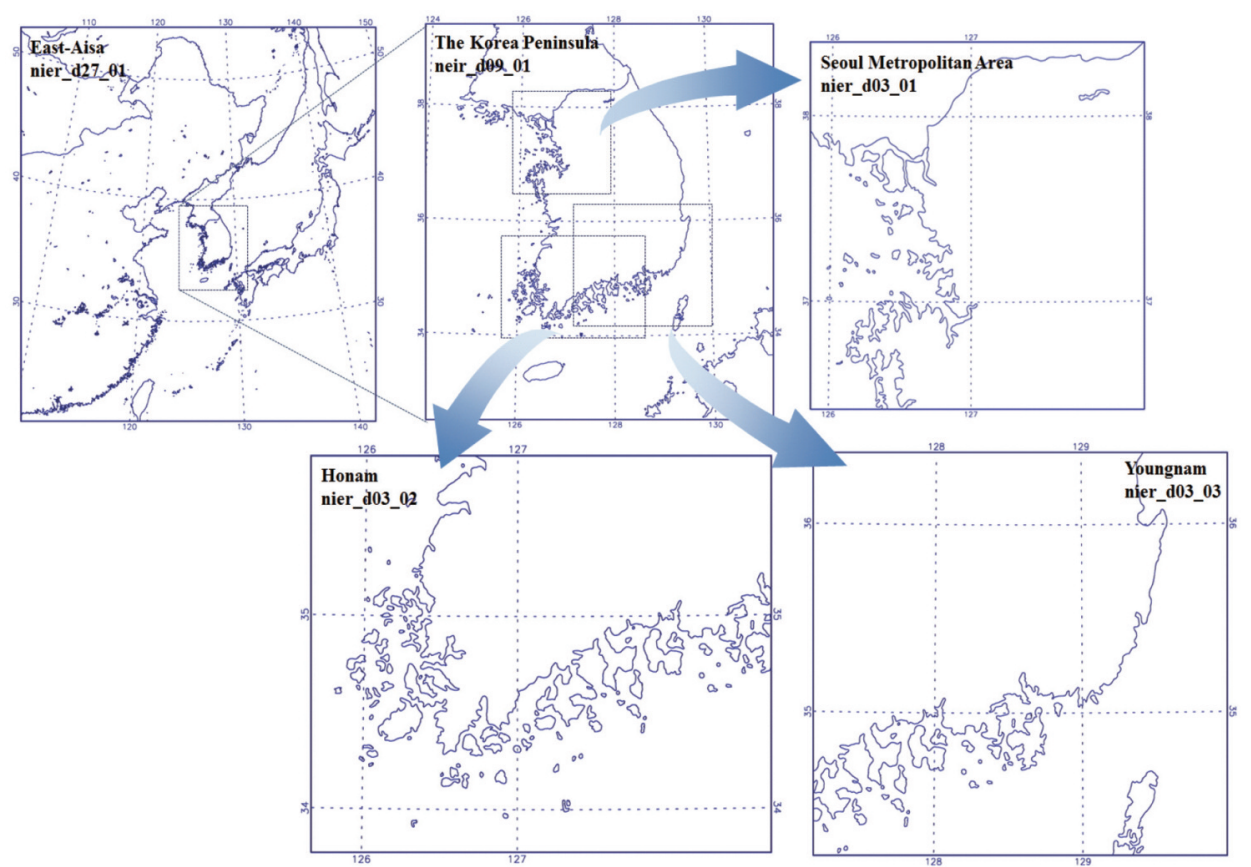

Figure 1. Standard domains for meteorological modeling

\section{(2) 수평 해상도}

동아시아 도메인의 격자 크기는 $27 \mathrm{~km}$ 또는 $30 \mathrm{~km}$ 등으로 설정하고 있으나 진단 기상모델의 둥지 도메 인 격자 비율이 $1: 3$ 이기 때문에 많은 연구에서 정수 로 표현이 가능한 $27 \mathrm{~km}$ 로 설정하고 있다(김순태, 2011; 이용미 등, 2009; 정주희 등, 2007). 한반도 도메인은 북한일부 지역을 포함한 남한 전역과 주변 의 바다를 충분히 포함하는 모델링 도메인으로 $9 \mathrm{~km}$ 격자 크기가 주로 사용된다. 권역규모 도메인은 서 울·경기·인천 및 그 주변지역을 포함하는 수도권지 역, 광양 - 여수 · 광주 및 그 주변지역을 포함하는 호 남권역, 울산 · 부산 · 대구 및 그 주변지역을 포함하
는 영남권역 등의 특정권역에 대한 모델링 도메인을 나타내며, $3 \mathrm{~km}$ 격자 크기가 주로 사용된다. 다만, 권 역규모 도메인 내의 특정 관심지역에 대하여 대기질 모델링을 수행할 필요가 있는 경우에는 관심지역의 도메인을 별도로 설정할 수 있다. 도시규모 도메인은 도시와 그 주변지역을 포함하는 정도의 수평규모로 격자크기는 $1 \mathrm{~km}$ 가 일반적이다. 미세규모 도메인은 극히 좁은 지역에 대하여 상세한 지형효과를 파악하 기 위해 설정하며 격자 크기는 $0.333 \mathrm{~km}$ 로 초고해상 도 도메인이다. 국가 대기정책 수립 및 평가에 사용 되는 기상 및 대기질 모델링의 표준 도메인은 Table 2 및 Table 3에서 제시하는 설정사항(원점, 지동투 영법, 격자크기 및 개수 등)으로 구성할 것을 권고하 
Table 3. Standard domains for air quality modeling

\begin{tabular}{c|c|c|c|c|c}
\hline \hline Domain Center & \multicolumn{5}{|c}{ Lambert conformal conic } \\
\hline Coordinate System & \multicolumn{5}{|c}{$36^{\circ} \mathrm{E}, 38^{\circ} \mathrm{N}$} \\
\hline Standard parallel & \multicolumn{5}{|c}{$60^{\circ}$} \\
\hline \multirow{2}{*}{\begin{tabular}{c} 
Domain Name \\
\cline { 1 - 6 }
\end{tabular}} & Eastern Asia & the Korea Peninsula & Seoul Metro -politan Area & Honam & Youngnam \\
\cline { 2 - 6 } & nier_d27_01 & nier_d09_01 & nier_d03_01 & nier_d03_02 & nier_d03_03 \\
\hline \multirow{2}{*}{$\begin{array}{c}\text { Grid Size and } \\
\text { number }\end{array}$} & $27 \mathrm{~km}$ & $9 \mathrm{~km}$ & $3 \mathrm{~km}$ & $3 \mathrm{~km}$ & $3 \mathrm{~km}$ \\
\cline { 2 - 6 } & $118 \times 125$ & $67 \times 79$ & $60 \times 63$ & $-22,500 \mathrm{~m}$ & $112,500 \mathrm{~m}$ \\
\hline X-origin & $-1,579,500 \mathrm{~m}$ & $-148,500 \mathrm{~m}$ & $1,500 \mathrm{~m}$ & $-450,000 \mathrm{~m}$ & $-396,000 \mathrm{~m}$ \\
\hline Y-origin & $-1,674,000 \mathrm{~m}$ & $-567,000 \mathrm{~m}$ & $-156,000 \mathrm{~m}$ & & $79 \times 73$ \\
\hline \hline
\end{tabular}

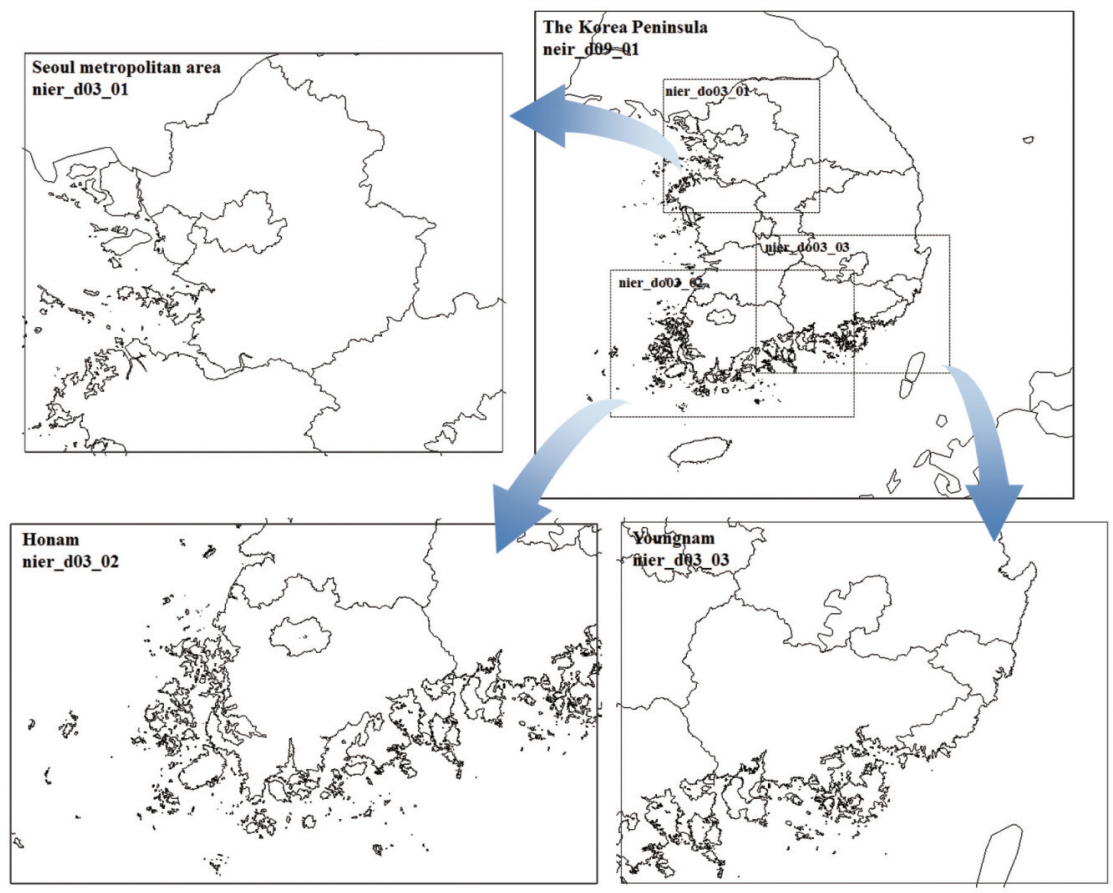

Figure 2. Standard domains for air quality modeling

며, 각각의 도메인을 Figure 1와 Figure 2와 같이 제 시하였다.

\section{(3) 수직 해상도}

대기질 모델링의 입력 자료로 사용되는 기상자료 를 생성하기 위하여 일반적으로 자료동화 기능을 가 지고 있는 진단 기상모델이 사용되며 이러한 진단 모 델의 수직층 개수는 일반적으로 30 개 이상이 사용된 다(황미경 등, 2011; 이종범 등, 2012). 구름형성 및 강수 과정을 정확하게 묘사하기 위해서는 일반적으 로 모델링 도메인의 최상층은 $50 \mathrm{hPa}$ 수준으로 설정
하여 경계층 상-하부에서의 기상과정 뿐만 아니라 모 델의 최상층의 기상 현상까지도 상세히 모사하기 위 하여 비교적 많은 개수의 수직층이 필요하다. 대기질 모델에 기상 자료를 효과적으로 반영하기 위해서는 동일한 수직 해상도가 필요하나 대기질 모델에 30 개 이상의 수직층을 적용하는 것은 불가능하거나 비효 율적임에 따라 진단 기상모델의 수직층에 따라 부분 적으로 선정한다. 혼합층 고도의 시간적 변화를 고려 할 때, 오후 최대 혼합층 고도 부근의 상-하부와 밤사 이 안정 조건에서 이루어지는 수직적 혼합고 지정 등 이 수직층 설정의 중요한 고려사항이다. 또한 낮 동 
Table 4. Recommended meteorological models

\begin{tabular}{c|c}
\hline \hline Meteorological model & Reference \\
\hline MM5 & Grell et al.(1994) \\
\hline RAMS & Pielke et al.(1992) \\
\hline WRF & Skamarock et al.(2005) \\
\hline \hline
\end{tabular}

안 혼합층 고도 하부의 비현실적인 대량 혼합을 방지 하기 위하여 대기질 모델의 최하층 두께가 $50 \mathrm{~m}$ 를 넘 지 않도록 설정할 것을 권고한다.

\section{IV. 대기질 모델의 입력자료}

\section{1. 대기질 모델링을 위한 기상 자료}

\section{(1) 기상 모델의 선정}

대기질 모델링 시 화학물질 조성, 수송, 제거 과정 등을 고려하기 위해서 시간과 공간에 대한 기상자료 는 필수적인 입력 자료이다. 기상자료의 작은 변화도 대기질 모델링 입력 자료로 사용될 경우 막대한 영향 을 주게 된다(Dolwick, 2002). 따라서 신뢰성 있는 대기질 모델링 결과를 얻으려면 양질의 기상입력 자 료 준비가 필요하며, 이를 위하여 기상장 모델링 시 물리 옵션들에 대한 민감도 분석 등을 충분히 실시하 여 대상영역에 대한 최적의 기상장 모델링 시스템 구 축이 필요하다. 기상 자료 생성에 있어 가장 널리 사 용하는 모델은 역학 기상 모델들로 Table 4에 제시 하였다. 이러한 모델들은 주어진 초기 상태로부터 특 정 변수들을 계산하기 위해서 모멘텀, 열역학, 습도 등의 기초 방정식들을 이용한다.

\section{(2) 기상 모델링을 위한 입력자료 준비}

\section{1) 초기 및 경계조건}

기상모델을 실행하기 위하여서는 가장 기본적으로 초기조건과 경계조건을 입력하여야 하며, 이러한 초 기장으로는 NCEP (National center for Environmental Prediction)의 FNL (Final Analyses) 재분석 자료 와 국내 기상청에서 매일의 일기예보용으로 실행하 는 RDAPS 결과를 이용할 수도 있다. NCEP의 재분 석 자료는 매 6 시간 마다 격자 간격 1 도로 출력되는 자료이며 격자의 남북거리는 $110 \mathrm{~km}$ 정도 된다. 한편
기상청의 RDAPS(Regional Data Assimilation and Prediction System)는 일기예보용으로 매일 실행되 고 있으며 매 3 시간 마다 격자간격 $30 \mathrm{~km}$ 와 $10 \mathrm{~km}$ 로 출력되고 있다.

\section{2) 기상 관측 자료}

모델 실행에서 기상관측 자료는 초기장 생성과 관 측자료에 의한 자료동화에 사용되며 모델결과의 평 가에도 사용되므로 적절하고 정확한 관측자료를 사 용하여야 한다. 일반적으로 이러한 관측 자료에는 기 상청의 기상대나 기상관측소에서 관측되는 지상기상 자료가 있으며, 기상청의 무인기상관측소(Automatic Weather Station; AWS)에서 생산되는 자료의 경우 에는 관측소 주변의 지형이나 건물 등을 파악하여 공 간 대표성 여부를 검토하여야 하며 기기 작동이상에 의한 자료의 오류를 검출해 내는 전처리 과정을 시행 한 후 사용하여야 한다(이화운 등, 2005).

우리나라에는 현재 7 개소(백령도, 오산, 광주, 흑 산도, 고산, 포항, 속초)의 고층기상 관측소에서 하루 2회 또는 4회 라디오 존데(Rawin Sonde) 관측을 실 시하고 있으며, 이들 자료는 신뢰성이 충분히 확보된 양질의 자료이다. 기상모델의 경우 지상뿐 아니라 상 층기상까지 잘 모사 되어야 대기질 모델에 사용되므 로 이들 상층기상자료는 매우 유용하며 자료동화에 적극 활용되어야 한다. 또한 입수 가능한 북한지역, 중국, 일본 등 동아시아 지역의 상층기상자료 역시 활용할 수 있다.

기상청에서 정기적으로 관측하는 정규 기상관측 자료 이외에 해상에 설치한 해상기상 관측용 부이 (buoy)자료, 공항기상대, 전국 수문관측소 자료 등도 이용가능하다. 또한 현재 기상 자료 생산을 위하여 이용하기 용이한 위성 자료로는 MODIS(MODerate resolution Imaging Spectroradiometer) 등을 들 수 있다. MODIS 자료는 지표면 온도와 그 밖의 지면 의 물리적인 상태, 식생의 피복 상태 등의 자료가 이 용 가능하며 이 자료들을 기상모델에 포함된 지면모 델 구동에 활용할 수 있다.

\section{3) 지형고도 및 토지이용 자료}

$\mathrm{MM} 5$ 와 $\mathrm{WRF}$ 모델에는 미국 지리원에서 제작한 

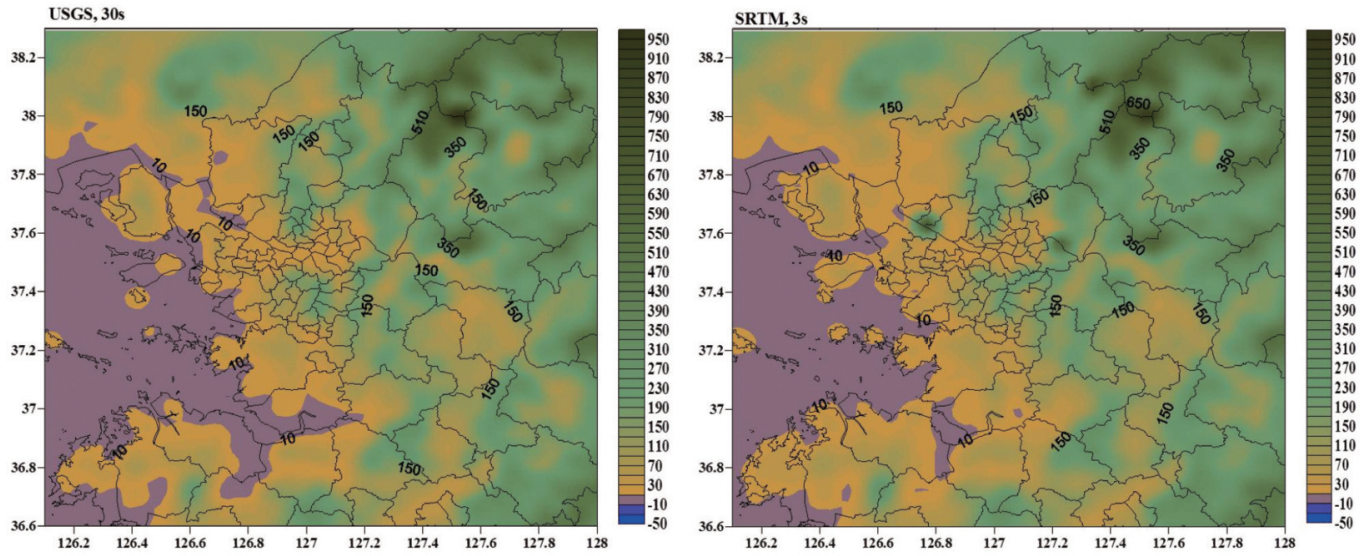

Figure 3. Topographic altitude comparison between USGS(30s) and SRTM(3s) data
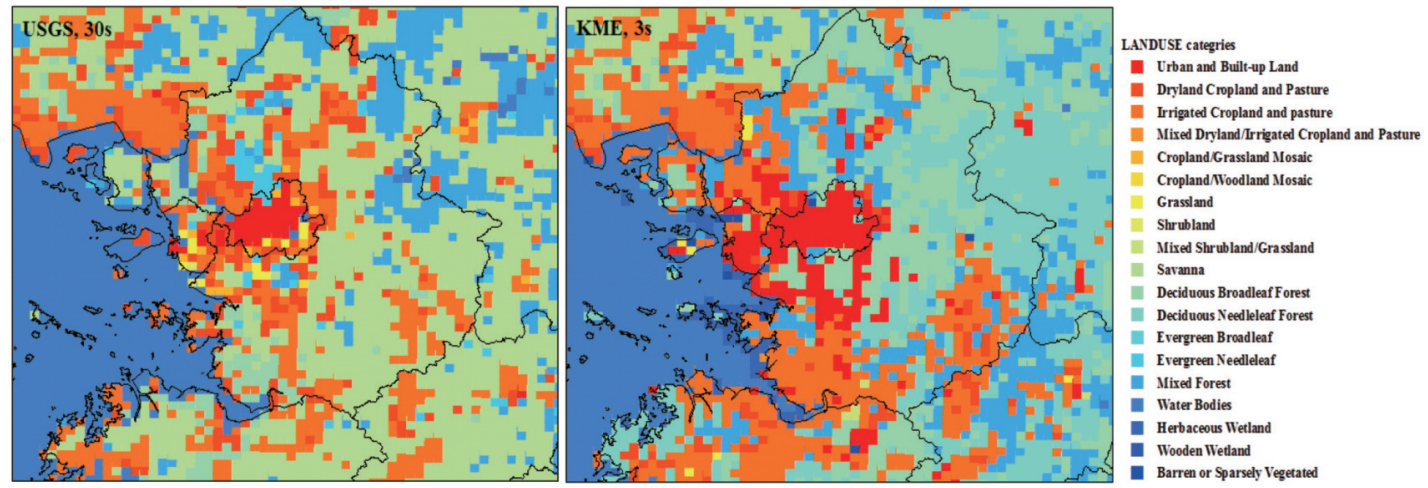

Figure 4. Landuse comparison between USGS(30s) and KME(3s) data.

지형고도 자료가 포함 되어 있다. 이 자료는 지구 전 체를 포괄하며 자료의 해상도는 여러 가지로 이루어 져 있는데 가장 높은 해상도 자료는 30 초 $\times 30$ 초 자 료로 수평거리 약 $900 \mathrm{~m}$ 이다. 국립환경과학원에서는 국내 지형자료를 보다 정확히 모사하기 위해서는 미 국 지리원의 자료에 비하여 최근에 산출된 3 초 $\times 3$ 초 간격의 자료인 SRTM (Shuttle Radar Topography Mission)의 사용을 권고하고 있다(Figure 3). 이에 국립환경과학원에서는 $\mathrm{WRF}$ 를 이용한 국가 대기정 책 수립 및 평가를 위한 기상 모델링 수행에 필요한 권역규모 도메인의 지형고도자료(SRTM)를 제공하 고 있다(국립환경과학원, 2012).

$\mathrm{MM} 5$ 와 WRF에 포함되어 있는 토지이용도 자료는 미국 지질조사소(US Geological Survey; USGS)에 서 작성한 해상도 30 초 $\times 30$ 초 자료이며, 토지이용도 의 종류는 24 종류이다. 그러나 USGS 자료의 경우
비교적 오래된 인공위성자료를 활용한 것으로 현재 의 우리나라 토지이용도와의 차이가 크다(Figure 4). 따라서 최근 연구에서는 USGS 자료를 대신하여 환 경부에서 제공하는 중분류토지피복을 이용한 토지이 용도 자료를 활용하고 있다(문윤섭 - 구윤서, 2006; 강윤희 등, 2008). 따라서 국립환경과학원에서는 $\mathrm{WRF}$ 를 사용하여 국가 대기정책 수립 및 평가를 위 한 기상 모델링을 수행하는 경우, 권역규모 도메인의 토지이용도자료는 환경부의 중분류 자료를 이용한 고해상도 토지이용 자료 제공하고 있다.

\section{2. 대기질 모델링을 위한 배출량 자료 준비}

(1) 인위적 배출량 및 자연 배출량

배출량 모델 실행을 위한 인위적 배출량 자료의 경 우에는 모델링 기간 동안 모델링 영역에서의 정확한 
배출량 자료가 준비되어야 하지만 이용 가능한 자료 가 없는 경우에는 국가 대기오염물질 배출량 자료를 우선적으로 사용해야한다. 우리나라의 경우에는 국 립환경과학원의 대기정책지원시스템 (Clean Air Policy Support System: CAPSS)을 통해 산정된 국 가 대기오염물질 배출량을 사용하여야한다. 우리나 라는 중국 등 동아시아지역으로부터 많은 영향을 받 고 있어 많은 연구들에서 INTEX (Intercontinental Chemical Transport Experiment)-B 또는 $\mathrm{ACE}$ (Aerosol Characterization Experiments)-Asia 등 의 동북아시아의 배출량을 사용하고 있다(김순태, 2011; 배창한 등, 2012; 이용미 등, 2009).

식물이나 토양에서 배출되는 자연 배출량은 VOC, $\mathrm{NOx}, \mathrm{CO}$ 배출량에 기여함에 따라 자연 배출량 산정 모델을 활용하는 것이 필요하다. 화산 배출량과 같은 자연 배출량은 모델링 영역에서 존재 시 대기질 문제 를 야기할 수 있음으로 이러한 배출량을 포함하는 것 이 필요하다.

\section{(2) 부수적 자료 작성}

배출량 모델 실행을 위하여 작성된 인위적 배출량 (국가 대기오염물질 배출량 등)은 모델의 격자정보, 시간 및 화학종에 따라 할당되어야만 대기질 모델의 입력자료로 사용될 수 있다. 따라서 시·공간 및 화학 종 할당을 위한 자료 작성이 필요하다. 시간 할당 자 료는 연간 배출량을 시간별, 주간별, 월별 배출량으 로 변환하는데 필요하며, 화학종 할당 자료는 총 $\mathrm{VOC}$ 와 미세먼지 등의 국가 배출량을 대기질 모델에 서 필요로 하는 입력자료의 형태로 변환하는데 사용 된다. 행정구역별 국가 배출량의 공간할당은 모델링 영역의 격자 정보 및 대용자료(surrogate)를 필요로 하며, 지리정보시스템(Geographic Information System: GIS)을 활용하여 이루어진다.

대기질 모델링의 입력자료로 사용되는 자연적 배 출량은 오존 등 광화학반응에 의하여 생성되는 2 차 대기오염물질의 모사에 중요한 역할을 하므로, 정확 한 자연 배출량 산정이 필요하다. 이러한 자연적 배 출량 산정 모델 실행을 위해서는 토지이용도, 식생 및 기상 자료 등이 필요하다.

\section{$\mathrm{V}$. 결 론}

지금까지 대기정책 수립과 평가에 필요한 대기질 모델링 실행을 위하여 대기질 모델링 표준 방법론을 마련하고자 하였다. 본 연구에서는 대기질 모델링 가 이드라인 중 대기질 모델링 수행을 위한 모델 선정, 도메인, 해상도 등의 공통사항과 대기질 모델링 입력 자료 등의 일반적인 사항에 대하여 제시하였다.

대기질 모델 선정을 위해 고려할 사항은 소스코드 가 공개된 모델로써 모델링 수행의 안정성이 확보된 모델로 최신의 이론 및 기능뿐만 아니라 기상 및 배 출량 모델에 대한 사용 가능 여부 등이며, 모델링 기 간 선정시에는 다양한 기상 조건을 포함할 수 있는 오염물질별 대표 계절이나 1 년 등의 긴 기간으로 환 경기준 초과 일을 포함하도록 제시하였다. 본 연구에 서는 대기 정책 수립 및 평가와 관련한 모델링 수행 시에 필요한 도메인 정보를 제시하고 있으며, 본 도 메인 영역은 동아시아 영역 $(27 \mathrm{~km})$ 과 한반도 영역 $(\mathrm{km})$ 과 수도권역, 호남권역 및 영남권역 등의 권역 규모 도메인 $(3 \mathrm{~km})$ 등이다. 또한 수직해상도로 진단 기상 모델의 경우 30 개 이상의 수직층을 권고하며, 최상층은 $50 \mathrm{hpa}$ 로 권고하였다.

본 연구에서는 대기질 모델 수행을 위한 입력자료 로써 기상 모델 및 배출량 모델에 대한 선정과정과 입력자료에 대한 방법론을 제시하고 있다. 본 연구를 통해 NCEP의 FNL 분석 자료와 기상청의 RDAPS 자료 등의 초기 및 경계 조건을 위한 입력자료를 제 시하였으며, 지상기상관측자료, 상층기상자료와 위 성 자료 등의 활용에 대해 밝혔다. 지형고도의 경우 30 초 간격의 USGS와 3 초 간격의 SRTM를 소개하였 으며, 토지 이용도 자료로는 USGS(30초)와 환경부 중분류 자료인 $\mathrm{KME}(3 \mathrm{~s})$ 의 활용을 권고하고 있다. 배 출량 자료의 경우 국가대기오염물질 배출량의 사용 을 권고하였고, 이와 더불어 동아시아 영역에 대해 INTXEX-b, ACE Asia 배출량과 자연 배출량 및 배 출량 처리를 위한 부수적 자료의 작성이 필요함을 언 급하였다.

지금까지 대기질 모델링 수행시 모델링 수행에 필 요한 공통적인 설정 사항과 입력자료 들에 대해 알아 
보았다. 이러한 대기질 모델링에 필요한 주요 요소에 대한 분석을 통해 대기질 모델링 수행시 발생 가능한 문제를 최소화하며, 모델링 수행의 투명성을 확보할 수 있을 것으로 판단된다. 또한 추후 대기 정책 수립 및 평가를 위한 모델링 수행을 위한 가이드라인으로 활용되어 일관된 정책 수행과 평가에 기여할 수 있을 것으로 판단된다.

\section{참고문헌}

국립환경과학원, 2010, 대기질 모델링 가이드라인 (안) 마련 연구.

국립환경과학원, 2012, 대기질모델링 정보자료 제 공을 위한 자료공개 시스템 구축2.

강윤희, 김유근, 오인보, 황미경, 강재은, 2008 , 상 세 토지피복도 입력에 따른 수도권 대기질 모델링 개선, 한국대기환경학회 춘계학술대 회 논문집, 557-558.

김순태, 2011, 2007년 6월 수도권 오존모사 V 배출량 변화에 따른 오존농도 예측 시 민감 도 기법 적용, 한국대기환경학회지, 27(6), 772-790.

김순태 · 이종범, 2011 , 대기질 모사를 통한 인접지 역 배출량이 광양만 오존농도에 미치는 영향 분석 - 2010년 6월 사례를 중심으로, 한국 대기환경학회지, 27(5), 504-522.

김운수, 2002 , 수도권 대기오염의 공간분포 특성을 고려한 지속가능한 개발방향과 과제, 경기 논단, 70-73.

김희강, 강충민, 조기철, 최민규, 이종억, 지동영, 이혁수, 이향림, 동종인, 박세옥, 서성석, 박 창규, 남은실, 선우영, 박영재, 김광진, 여현 구, 1999, 도시지역 광화학반응과 2차오염 물질 생성에 관한 연구, 국립환경과학원.

문난경, 김순태, 서지현, 2011, PBL Scheme에 대 한 $\mathrm{WRF}-\mathrm{CMAQ}$ 민감도 분석, 한국대기환 경학회지, 27(6), 791-804.

문윤섭 - 구윤서, 2006, 수도권지역에서 수치 토지 피복지도 작성을 통한 대기환경부문 활용사
례 연구 - MM5내 기온 및 바람장의 민감도 분석과 식생분포에 기인한 $\mathrm{VOC}$ 배출량 및 $\mathrm{CO} 2$ 플럭스의 실시간 산정을 중심으로-, 한국대기환경학회지, 22(5), 661-678.

배창한, 김순태, 우정헌, 김철희, 장임석, 김종춘, 2012, 동북아시아 배출량 목록 불확실성에 따른 오존 민감도 변화 고찰, 한국대기환경 학회 춘계학술대회 논문집, 117.

유 철, 이대균, 이용미, 이미향, 홍지형, 이석조, 2011, 수도권 지역의 대기환경관리 시행계획 추진 결과 평가를 위한 대기질 모델링 적용 방법, 한국환경과학회지, 20(12), 1647-1661.

이용미, 이현주, 유 철, 송정희, 김지영, 홍지형, 2009 , 수도권 지역에서 대기질 측정망 자료 를 이용한 광화학 모델의 이동오염원 배출량 검증, 한국대기환경학회지, 25(5), 369-381. 이종범, 이미혜, 조석연, 손장호, 이강웅, 김유근, 오인보, 이화운, 전의찬, 구윤서, 조용성, 최 기주, 문태훈, 노기환, 문윤섭, 2005 , 대도 시 대기질 관리방안 조사연구(광화학 대기 오염 생성과정 규명과 저감대책 수립), 국립 환경과학원.

이종범, 김재철, 천태훈, 2009 , 위성자료를 이용한 MM5 4차원자료동화가 광화학모델의 정확 도에 미치는 영향 고찰, 한국대기환경학회 지, 25(4), 264-274.

이종범, 김재철, 장윤정, 2012 , 관측과 기상모델을 이용한 추천지역의 도시열섬현상 연구, 한 국대기환경학회지, 28(2), 119-130.

이화운, 최현정, 이강열, 2005 , 상세한 하부 경계 조건과 관측값 객관분석이 복잡지형의 대기 흐름장 수치모의에 미치는 효과, 한국기상 학회지, 41(1), 73-87.

정주희, 김유근, 문윤섭, 황미경, 2007 , 수도권지역 대기질 예측을 위한 기상장 모델의 바람장과 온도장 비교 연구, 한국대기환경학회지, 23(6), 640-652.

홍성철, 이재범, 최진영, 문경정, 이현주, 홍유덕, 이석조, 송창근, 2012 , 동아시아지역의 CMAQ 
대류권 오존 모의에 화학적 측면 경계조건이 미치는 효과, 한국대기환경학회지, 28(5), 581-594.

홍유덕, 한진석, 공부주, 이상욱, 신선아, 김영미, 이석조, 2003 , 고농도 오존발생과 광화학오염 현상 규명을 위한 연구(III), 국립환경과학원. 홍지형, 이상보, 이대균, 유 철, 이용미, 이미향, 2011, 국가 대기정책 수립 및 평가를 위한 대 기질 모델링 가이드라인, 국립환경과학원. 황미경, 오인보, 김유근, 2011 , 도시형 중규모 기상 모델을 이용한 연안도시 해풍전선 발달 분 석, 한국대기환경학회지, 27(4), 416-425. 환경부, 2010, 수도권 대기환경개선에 관한 특별법, $1-4$.

Byun, D. W., Kim, S. T. and Kim, S. B., 2007, Evaluation of CMAQ Results for the Simulation of a High Ozone Episode in the Houston-Galveston-Brazoria Metropolitan Airshed, Atmospheric Environmental, 41, 837-853.

Dolwick, P. D., 2002, USEPA/OAQPS Meteorological Modeling Analyses, the 2002 Ad Hoc Meteorological Modeling Meeting.

ENVIRON International Corporation, 2004, Annual PM Modeling and Analysis of Episode Aggregation Uncertainties for Annual Average PM2.5 and Visibility Modeling, ENVIRON.

ENVIRON International Corporation, 2006, CAMx User's Guide version 4.40.

Grell, G., Dudhia, J. and Stauffer, D., 1994, A description of the Fifth-Generation Penn State/NCAR Mesoscale Model(MM5), NCAR Technical Note, NCAR/TN.
Hogrefe, C., Rao, S. T., Zurbenko, I. G. and Porter, P. S., 2000, Interpreting the information in time series of ozone observations and model predictions relevant to regulatory policies in the eastern United States, Bull. Amer. Met. Soc., 81, 2083-2106.

Pielke, R. A., Cotton, W. R., Walko, R. L., Tremback, C. J., Lyons, W. A., Grasso, L. D., Nicholls, M. E., Moran M. D. , Wesley, D. A., Lee, T. J. and Copeland, J. H., 1992, A Comprehensive Meteorological Modeling System RAMS, Department of Atmospheric Science, Colorado State University.

Skamrock, W. C., Klemp, J. B., Dudhia, J., Gill, D. O. and Barker D. M., Wang, W. and Powers, J. G., 2005, A description of the Advanced Research WRF version 2., NCAR.

System Application International, 1996, User's Guide to the Variable-Grid Urban Airshed Model(UAM-V), SYSAPP-95/027, San Rafael.

U.S. Environmental Protection Agency, 2007, Guidance on the Use of Models and Other Analyses for Demonstrating Attainment of Air Quality Goals for Ozone, PM2.5, and Regional Haze, 1253.

U.S. Environmental Protection Agency, 1998, Models-3 volume 9b: User Manual, Draft EPA report, U.S. Environmental Protection Agency.

기상청, http://web.kma.go.kr/aboutkma/biz/ forecast04.jsp 